\title{
Comparative Power Quality analysis of Conventional and Modified DSTATCOM Topology
}

\author{
Pradeep Kumar \\ NIT Sikkim, Ravangala 737139 INDIA \\ pradeep@nitsikkim.ac.in
}

\begin{abstract}
In this paper, the two topologies of Distribution Static Compensator (DSTATCOM) such as conventional DSTATCOM and modified DSTATCOM with their performances are investigated in terms of power quality improvement. Normally the DSTATCOM has shunt voltage source inverter (VSI) connected to point of common coupling (PCC) through the interfacing inductor. It is possible to modify DSTATCOM by connecting a capacitor in series with the interface inductor at the point of common coupling. This Modified topology requires a lower value of dc link voltage across the $\mathrm{dc}$ storage capacitor of voltage source inverter (VSI) for compensation of source currents, when compared with the conventional DSTATCOM topology. The reference signal for PWM generator is generated using synchronous reference frame theory and Indirect PI theory. A detailed simulation study to compare the performances of conventional and modified topologies are carried out using MATLAB 7.1 and the superior features of modified DSTATCOM topology are established.
\end{abstract}

Keywords: Distribution static compensator (DSTATCOM), Indirect PI (IPI) controller, Point of common coupling (PCC), Synchronous reference frame (SRF) controller, Voltage-source inverter (VSI).

\section{Introduction}

Three-phase power systems are facing severe power quality problems such as poor voltage regulation, large reactive power burden, harmonics current, and load unbalancing. The power quality problems and their improvement techniques are reported in the literature over the years [1-8]. The Distribution Static Compensator (DSTATCOM) is one of the power quality improvement device which is used to provide reactive power for improving voltage regulation, to reduce harmonics in the source currents, and to balance the supply currents when the loads are unbalanced and nonlinear. There are various topological structures of the DSTATCOM are reported in the literature such as a voltage source converter (VSC) with four legs [9], three single-phase VSC [8], three-leg VSC with split capacitors[9], and three-leg VSC with a zig-zag transformer [10]. To generate reference signal for PWM generator in order to provide pulses for the control of VSI of DSTATCOM, many control techniques are presented in the literature, viz., instantaneous reactive power theory ( $p-q$ theory), synchronous reference frame theory, power balance theory, etc. [6,8,9]. Many soft computing based control algorithms such as neural network, fuzzy logic and adaptive neuro-fuzzy etc [11-14], have been also adopted for the control of VSI based DSTATCOM.

Due to less computation time and easily availability of input variable, Indirect PI and synchronous reference frame theory based control algorithms are implemented in three phase shunt connected DSTATCOM for compensation of unbalanced and nonlinear loads.

This paper deals with the comparative performance analysis of conventional and modified DSTATCOM topology for three phase four wire systems. This modified topology requires lesser value of dc link voltage when compared with existing conventional topology.

The paper is organized as follows. After starting with Introduction in section 1, section 2 briefly presents about the DSTATCOM topology in terms of conventional and modified approach. Section 3 gives a detailed description of control signals for generation of reference signals for VSI valves. Section 4 describes about simulation results for the conventional and

Received: November $4^{\text {th }}, 2017$. Accepted: December $29^{\text {th }}, 2017$ DOI: 10.15676/ijeei.2017.9.4.11 
modified DSTATCOM topologies and finally section 5 represents conclusion of this research work.

\section{DSTATCOM Topology}

Distribution static compensator (DSTATCOM) is just like as a shunt active filter which is attached in parallel to the load and source at PCC. Here the DSTATCOM Topology is categorized in terms of conventional and modified DSTATCOM topology as follows:

\section{A. Conventional DSTATCOM Topology}

Single line diagram of conventional DSTATCOM topology is shown in Figure1. Conventional topology has VSI which is coupled in parallel to the load at the PCC through interface inductor $\left(\mathrm{L}_{\mathrm{f}}\right)$. The main task of the interface inductor is for proper shaping of the filter currents while tracking the reference filter currents. The capacitance $\mathrm{C}_{\mathrm{dc}}$ is the dc storage capacitor used for maintaining the input voltage of VSI at reference value of $\mathrm{V}_{\text {dcref }}$. However, the voltage across $C_{d c}$ is instantaneously varying quantity and is denoted as $\mathrm{v}_{\mathrm{dc}}$.

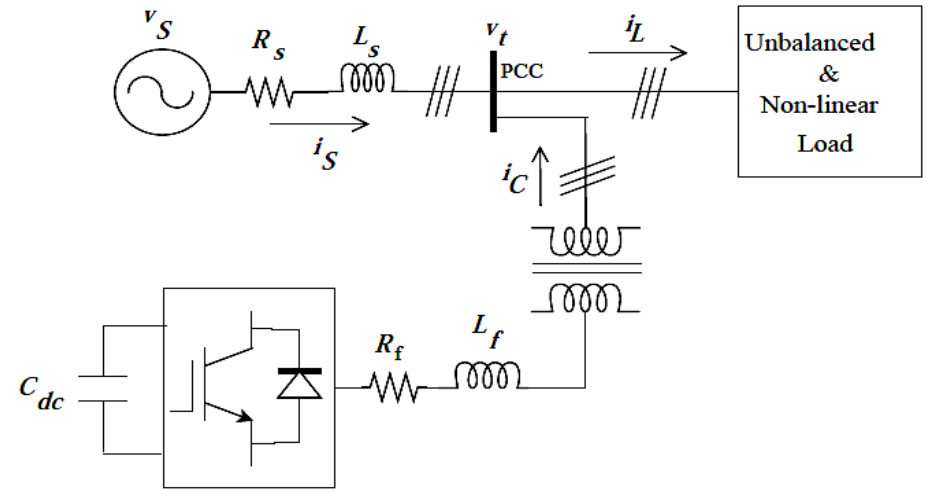

Figure 1. Conventional DSTATCOM

Design of DC Capacitor $\left(C_{d c}\right)$

In order to drive the compensated currents, the value of $V_{\text {dcref }}$ should to be 1.6 times the peak value of system line voltage $\left(\mathrm{V}_{\mathrm{lm}}\right)$ as given in [15-17]. Once the value of $\mathrm{V}_{\mathrm{dcref}}$ is selected, the value of $\mathrm{C}_{\mathrm{dc}}$ can be determined from the transient period in the system and its ability to regulate under this condition. Consider the STATCOM is connected to an $x \mathrm{kVA}$ system and deals with $0.5 x \mathrm{kVA}$ and $1.5 x \mathrm{kVA}$ handling capability under transient conditions for ' $p$ ' cycles. The energy in $x \mathrm{kVA}$ system in joules is $x X 1000$ joules. An increase in system $\mathrm{kVA}$ load results a decrease in $\mathrm{v}_{\mathrm{dc}}$ during transient and vice versa. Allowing a maximum of $12.5 \%$ variation in $\mathrm{v}_{\mathrm{dc}}$ during transients, the differential energy $\left(\Delta \mathrm{E}_{\mathrm{c}}\right)$ across $\mathrm{C}_{\mathrm{dc} 1}$ (for increase in load) is given as

$$
\Delta E_{C}=C_{d c 1}\left[\left(1.6 V_{l m}\right)^{2}-\left(1.4 V_{l m}\right)^{2}\right] / 2
$$

The change in system energy $\left(\Delta \mathrm{E}_{\mathrm{s}}\right)$ for load change from $x \mathrm{kVA}$ to $1.5 x \mathrm{kVA}$ in joules is

$\Delta \mathrm{E}_{\mathrm{s}}=(1.5 x-x) 1000 \mathrm{p} \mathrm{T}$

Where, $\mathrm{T}$ is the time period of system voltage and ' $\mathrm{p}$ ' is the period of transient. Therefore from equations

1 and $2, \mathrm{C}_{\mathrm{dc} 1}$ is given as

$$
C_{d c 1}=2(1.5 x-x) 1000 p T /\left(\left(1.6 V_{l m}\right)^{2}-\left(1.4 V_{l m}\right)^{2}\right]
$$


Similarly, $\mathrm{C}_{\mathrm{dc} 2}$ is calculated for the case of decrease in load from $x \mathrm{kVA}$ to $0.5 x \mathrm{kVA}$, where $\mathrm{V}_{\mathrm{dc}}$ is allowed to increase up to $1.8 \mathrm{~V}_{\mathrm{lm}}$ from a reference value of $1.6 \mathrm{~V}_{\mathrm{lm}}$. The maximum of the obtained $\mathrm{C}_{\mathrm{dc} 1}, \mathrm{C}_{\mathrm{dc} 2}$ values is chosen as the dc storage capacitor $\mathrm{C}_{\mathrm{dc}}$.

\section{B. Modified DSTATCOM Topology}

The basic difference between conventional and modified topologies is the insertion of capacitor $C_{f}$ which is connected in series with the interface inductor $L_{f}$ as shown in Figure 2. Since $C_{f}$ is incorporated in between STATCOM and PCC, the voltage build up across $C_{f}$ plays a vital role for calculating the value of reference dc link voltage required for compensation in modified topology.

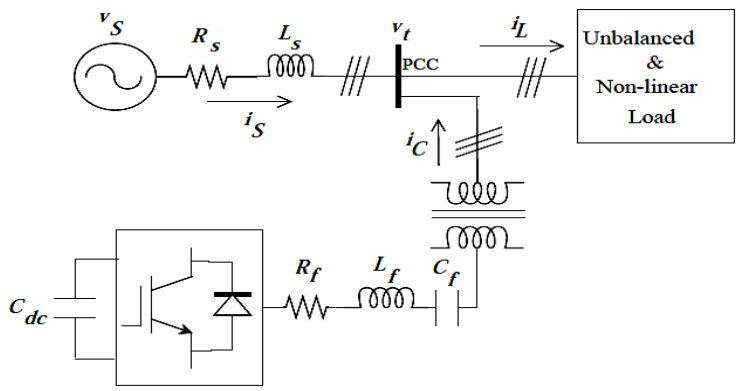

Figure 2. Modified DSTATCOM

Design of Series Capacitor $\left(C_{f}\right)$

Let the dc link voltage required for compensation in modified topology and conventional topology is denoted as $V_{\text {dcmref }}$ and $V_{\text {dcref }}$ respectively, $I_{\text {fmax } 1}$ represent the maximum value of fundamental filter current corresponding to the phase where reference filter current is maximum [17]. The VA rating of the PWM voltage source inverter (active filter) used in conventional topology is denoted as $\mathrm{VA}_{\mathrm{c}-\mathrm{AF}}$ (here the subscript ' $\mathrm{c}$ ' stands for conventional and 'AF' for active filter) and is given below in (4).

$$
V A_{c-A F}=\sqrt{3}\left(\frac{\sqrt{3} V_{d c r e f}}{2 \sqrt{2}}\right)\left(\frac{I_{f \max 1}}{\sqrt{2}}\right)
$$

The rating of the active filter with $\mathrm{V}_{\mathrm{dcmref}}$ as the input dc link voltage in modified topology, is represented as $\mathrm{VA}_{\mathrm{m}-\mathrm{AF}}$ (here the subscript ' $\mathrm{m}$ ' stands for modified) and is given below in (5).

$$
V A_{m-A F}=\sqrt{3}\left(\frac{\sqrt{3} V_{d c m r e f}}{2 \sqrt{2}}\right)\left(\frac{I_{f \max 1}}{\sqrt{2}}\right)
$$

The difference in (4) and (5) should be equal to the VA rating the series combination of the passive elements interface inductor and series capacitor in order to have proper compensation. Therefore,

$$
V A_{c-A F}-V A_{m-A F}=3\left(X_{C}-X_{L}\right)\left(\frac{I_{f \max 1}}{\sqrt{2}}\right)^{2}
$$

Where, $X_{C}=1 /\left(2 \pi f C_{f}\right), X_{L}=\left(2 \pi \mathrm{fL}_{f}\right)$ represents the reactance's of $C_{f}$ and $L_{f}$ respectively. Therefore from equations (4), (5) and (6), $1 / \mathrm{C}_{\mathrm{f}}$ can be determined as given below in (7), where $\omega=2 \pi f$ and the corresponding fundamental component of rms voltage $\left(v_{c f r m s}\right)$ developed across $\mathrm{C}_{\mathrm{f}}$, is given in (8).

$$
\begin{aligned}
& 1 / C_{f}=\frac{\omega\left(V_{d c r e f}-V_{d c m r e f}\right)}{2 I_{f \max 1}}+\omega^{2} L_{f} \\
& V_{c f r m s 1}=\left(\frac{I_{f \max 1}}{\sqrt{2}}\right) 1 / 2 \pi f C_{f}
\end{aligned}
$$




\section{Generation of Reference Signals}

Generation of reference signals for the PWM generator of VSI based DSTATCOM is achieved by Indirect PI [18] and synchronous reference frame control techniques $[8,19]$. The detail explanation of these control techniques have been given below:

\section{A. Indirect PI controller}

An error signal is obtained by comparing the reference voltage (set voltage) and the terminal voltage (rms value). This error is processed to a PI controller. The output of PI controller is the angle $\delta$. Figure 3 represents Indirect PI controller which generates angle $\delta$.

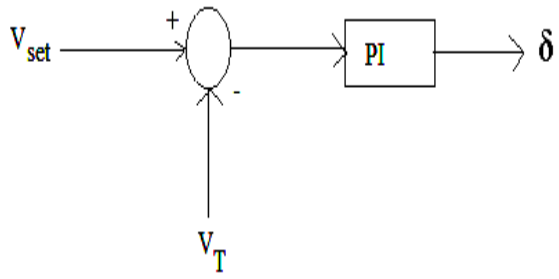

Figure 3. Indirect PI controller

From the angle $\delta$, three phase sinusoidal signal $\mathrm{V}_{\text {control }}$ is obtained as follows:

$$
\begin{aligned}
& \mathrm{V}_{\mathrm{A}}=\operatorname{Sin}(\omega \mathrm{t}+\delta) \\
& \mathrm{V}_{\mathrm{B}}=\operatorname{Sin}(\omega \mathrm{t}+\delta-2 \pi / 3) \\
& \mathrm{V}_{\mathrm{C}}=\operatorname{Sin}(\omega \mathrm{t}+\delta+2 \pi / 3)
\end{aligned}
$$

Three phase voltage signal $\mathrm{V}_{\mathrm{A}}, \mathrm{V}_{\mathrm{B}}$ and $\mathrm{V}_{\mathrm{C}}$ are shifted by $0^{\circ}, 120^{\circ}$ and $240^{\circ}$ respectively. Figure 4 represents phase modulation of control angle $\delta$. Sinusoidal signal $\mathrm{V}_{\text {control }}$ is fed to PWM signal generator in order to generate switching pulses for IGBT switches of the voltage source inverter valves. Figure 5 shows simulink model of DSTATCOM controller which consist sequence analyzer, discrete PI controller and phase modulation block to generate voltage signal for the PWM generator.

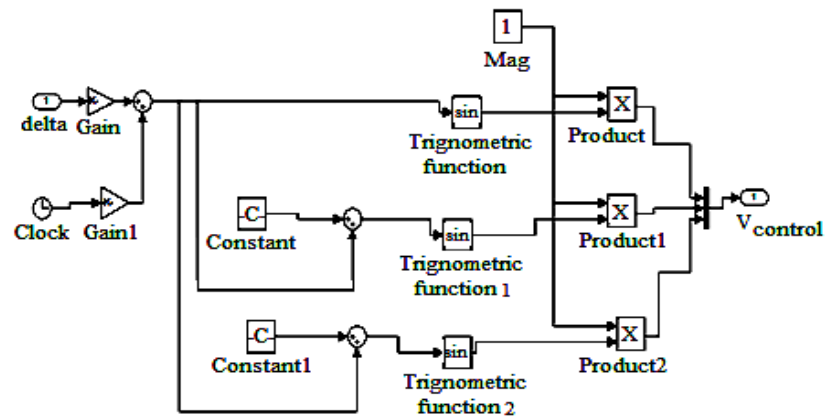

Figure 4. Phase Modulation of the control angle $\delta$

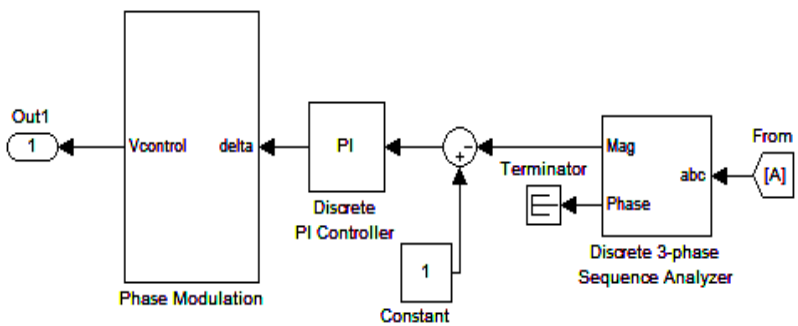

Figure 5. Simulink model of DSTATCOM controller 


\section{B. Synchronous Reference Frame Controller}

Figure 6 depicts step by step procedure for obtaining reference value of three phase compensator current from the three phase load current. The load currents from the $a-b-c$ frame are first converted to the $\alpha-\beta$ frame and then to the $d-q$ frame using the following formulation

$$
\begin{aligned}
& {\left[\begin{array}{l}
\mathrm{i}_{\mathrm{Ld}} \\
\mathrm{i}_{\mathrm{Lq}}
\end{array}\right]=2 / 3\left\{\begin{array}{crc}
\cos \omega \mathrm{t} & \cos (\omega \mathrm{t}-2 \pi / 3) & \cos (\omega \mathrm{t}+2 \pi / 3) \\
\sin \omega \mathrm{t} & \sin (\omega \mathrm{t}-2 \pi / 3) & \sin (\omega t+2 \pi / 3)
\end{array}\right)\left[\begin{array}{l}
\mathrm{i}_{\mathrm{La}} \\
\mathrm{i}_{\mathrm{Lb}} \\
\mathrm{i}_{\mathrm{Lc}}
\end{array}\right]} \\
& {\left[\begin{array}{l}
\overline{\mathbf{i}_{\mathrm{Ld}}} \\
\overline{\mathbf{i}_{\mathrm{Lq}}}
\end{array}\right]=\mathbf{G}(\mathbf{s})\left[\begin{array}{l}
\mathbf{i}_{\mathrm{Ld}} \\
\mathbf{i}_{\mathrm{Lq}}
\end{array}\right]}
\end{aligned}
$$

Here the DC voltage controller is designed as a proportional controller. The PCC voltage controller is designed as a PI controller. The output of the proportional $(\mathrm{P})$ controller at the $\mathrm{dc}$ bus voltage of DSTATCOM is considered as the current $\mathrm{i}_{\mathrm{Cd}}$ and The output of the proportional-integral (PI) controller at the PCC bus voltage of DSTATCOM is considered as the current $\mathrm{i}_{\mathrm{Cq}}$. $\mathrm{u}$ is a logical variable equal to (a) zero if PF is to be regulated (b) one if bus voltage is to be regulated. $K_{q}=1$ in latter case.

When $\mathrm{PF}$ is to be controlled, $K_{q}$ is determined by required power factor as follows

$$
\mathrm{K}_{\mathrm{q}}=\mathrm{Q}_{\mathrm{s}}^{*} / \frac{\mathrm{Q}}{\mathrm{Q}_{\mathrm{L}}}
$$

Where $Q_{S}^{*}$ reference reactive power supplied by source (at PCC) and $\bar{Q}_{L}$ is average reactive power defined by $\overline{\mathrm{Q}}_{\mathrm{L}}=\left|\mathrm{V}_{\mathrm{t}}\right| \overline{\mathrm{i}}_{\mathrm{Lq}}$

For unity power factor, $\cos \varphi=1$, so $\varphi=0$

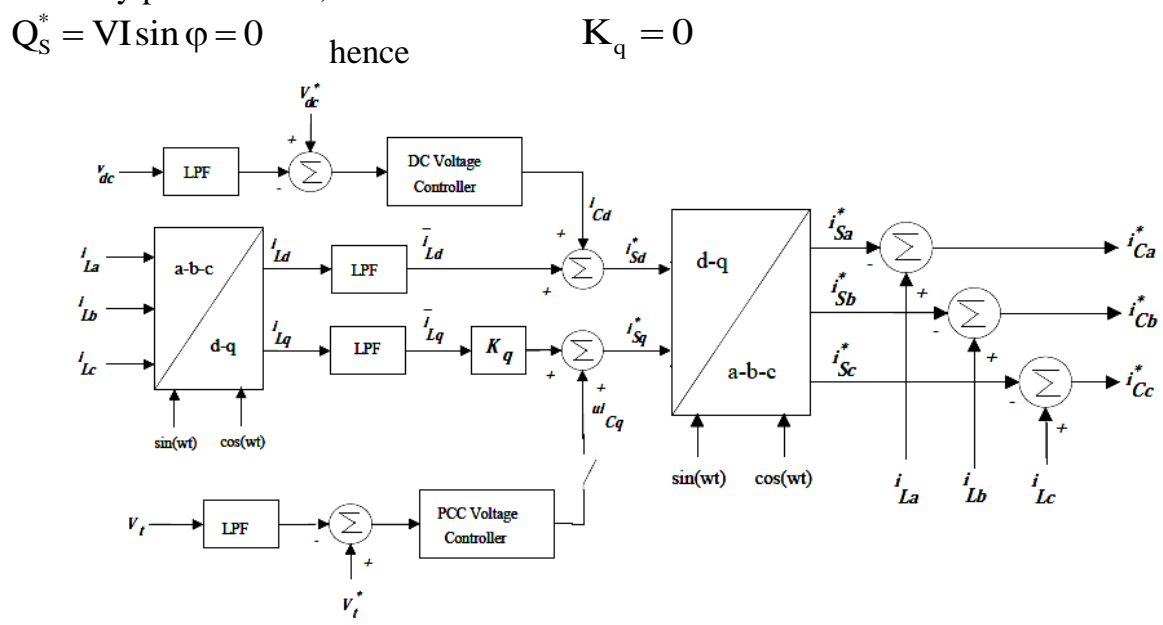

Figure 6. Synchronous Reference Frame control scheme

The desired source currents (in d-q component) are obtained as

$$
\mathbf{i}_{\mathrm{Sd}}^{*}=\overline{\mathbf{i}_{\mathrm{Ld}}}+\mathbf{i}_{\mathrm{Cd}}, \mathbf{i}_{\mathrm{Sq}}^{*}=\mathbf{K}_{\mathrm{q}} \overline{\mathbf{i}_{\mathrm{Lq}}}+\mathbf{u} \mathbf{i}_{\mathrm{Cq}}
$$

The reference for the source current in the $d-q$ frame are first converted to the $\alpha-\beta$ frame and then to the $a-b-c$ frame using the following formulation 


$$
\left[\begin{array}{l}
\mathbf{i}^{*}{ }_{\mathrm{sa}} \\
\mathbf{i}_{\mathrm{sb}}^{*} \\
\mathbf{i}_{\mathrm{sc}}^{*}
\end{array}\right]=2 / 3\left\{\begin{array}{cc}
\cos \omega \mathrm{t} & \sin \omega \mathrm{t} \\
\cos (\omega \mathrm{t}-2 \pi / 3) & \sin (\omega \mathrm{t}-2 \pi / 3) \\
\cos (\omega \mathrm{t}+2 \pi / 3) & \sin (\omega \mathrm{t}+2 \pi / 3)
\end{array}\right\}\left[\begin{array}{l}
i_{\mathrm{sd}}^{*} \\
i_{\mathrm{sq}}^{*}
\end{array}\right]
$$

The desired compensator currents $\left(\mathrm{i}_{\mathrm{Ca}}{ }^{*}, \mathrm{i}_{\mathrm{Cb}}{ }^{*}, \mathrm{i}_{\mathrm{Cc}}{ }^{*}\right)$ are obtained as

$$
\mathrm{i}_{\mathrm{Ca}}^{*}=\mathrm{i}_{\mathrm{La}}-\mathrm{i}_{\mathrm{Sa}}^{*}, \mathrm{i}_{\mathrm{Cb}}^{*}=\mathrm{i}_{\mathrm{Lb}}-\mathrm{i}_{\mathrm{Sb}}^{*}, \mathbf{i}_{\mathrm{Cc}}^{*}=\mathrm{i}_{\mathrm{Lc}}-\mathrm{i}_{\mathrm{Sc}}^{*}
$$

\section{Simulation results and analysis}

The models of the conventional and modified DSTATCOM topologies shown in Figure 1, Figure 2 respectively were build in MATLAB 7.1 simulation package and its sim power toolboxes to carry out simulation studies. The system parameters for the simulation are given in Table 1. The main intention in this simulation is to show two different performance aspects for both the conventional and modified DSTATCOM topologies: 1) Source current harmonic reduction and power factor Improvement under Indirect PI control; 2) Source current harmonic reduction and power factor Improvement under synchronous reference frame control. The total harmonic distortion (THD) measurements of source current are compared for Indirect PI and synchronous reference frame controls under both topologies and verified by the limits specified by the IEEE519 and IEC61000-3 harmonic standards [20].

Table 1. System Parameters for simulation

\begin{tabular}{l|l}
\hline \multicolumn{1}{c|}{ Parameter } & \multicolumn{1}{c}{ Values } \\
\hline $\begin{array}{l}\text { System Voltages (Three-phase) with } \\
\text { frequency }\end{array}$ & $\mathrm{V}_{\mathrm{L}-\mathrm{L}}(\mathrm{rms})=400 \mathrm{~V}, 50 \mathrm{~Hz}$ \\
\hline Feeder (Source) impedance & $\mathrm{Z}_{\mathrm{s}}=1+\mathrm{j} 0.628 \Omega$ \\
\hline Linear (Unbalanced) load & $\begin{array}{l}\mathrm{Z}_{\mathrm{la}}=22+\mathrm{j} 6.28 \Omega, \mathrm{Z}_{\mathrm{b}}=35+\mathrm{j} 18.84 \Omega, \\
\mathrm{Z}_{\mathrm{lc}}=70+\mathrm{j} 37.69 \Omega\end{array}$ \\
\hline $\begin{array}{l}\text { Nonlinear load(Three phase diode with } \mathrm{R}- \\
\text { L load) }\end{array}$ & $\mathrm{R}_{\mathrm{D}}=80 \Omega, \mathrm{L}_{\mathrm{D}}=400 \mathrm{mH}$ \\
\hline Power converter & $\mathrm{IGBTs} /$ diodes \\
\hline PWM switching frequency & $10 \mathrm{kHz}$ \\
\hline Inverter (VSI) parameters & $\mathrm{C}_{\mathrm{dc}}=1000 \mu \mathrm{F}, \mathrm{L}_{\mathrm{f}}=20 \mathrm{mH}, \mathrm{R}_{\mathrm{f}}=0.1 \Omega$ \\
\hline DC link voltage (DC side of Inverter) & $\begin{array}{l}\text { Conventional topology }\left(\mathrm{V}_{\mathrm{dcref}}=1.6 \mathrm{~V}_{\mathrm{ml}}=900\right. \\
\mathrm{V}) \\
\text { Modified topology }\left(\mathrm{V}_{\mathrm{dcmref}}=\mathrm{V}_{\mathrm{ml}}=\right.\end{array}$ \\
\hline Gains for the PI controller & $560 \mathrm{~V})$ \\
\hline Gains for the proportional controller & $\begin{array}{l}\text { Conventional topology }(\mathrm{Kp}=10, \mathrm{Ki}=0.1), \\
\text { Modified topology }(\mathrm{Kp}=1, \mathrm{Ki}=0.01)\end{array}$ \\
\hline Series capacitor (Series with interface \\
inductor)
\end{tabular}


A. Source current harmonic reduction and power factor Improvement under Indirect PI control

In this section, the voltage and current characteristic of the conventional and modified DSTATCOM systems in terms of harmonic compensation in source current and power factor improvement on source side are illustrated. Firstly the performance characteristic of the conventional DSTATCOM system is tested under Indirect PI control technique. Figure 7 depicts voltage and current waveform for Conventional DSTATCOM in Without DSTATCOM and With DSTATCOM condition.

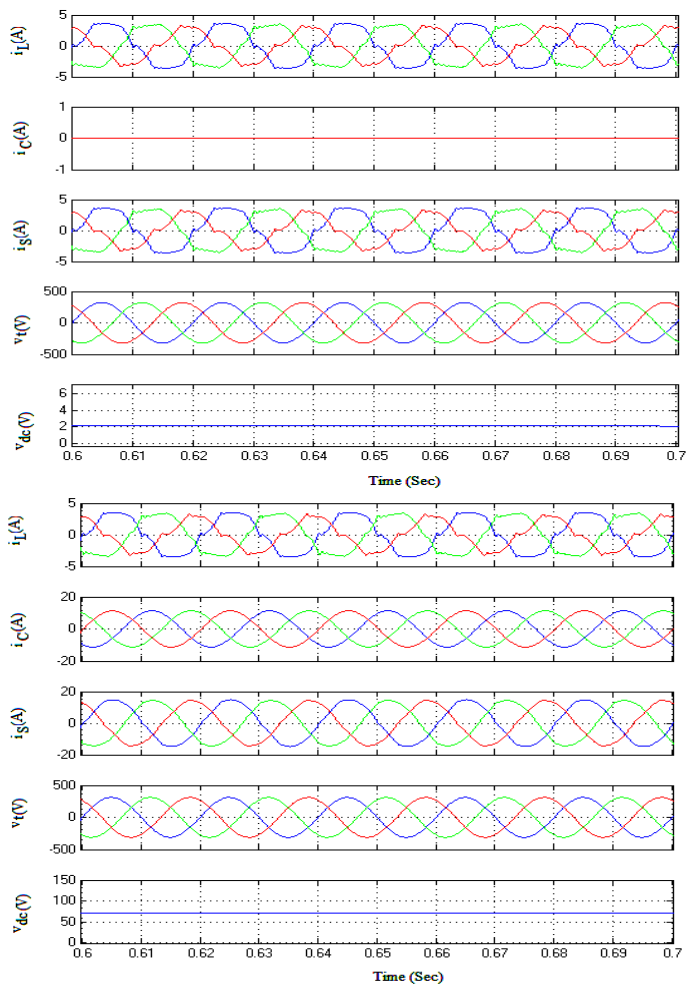

(a)

(b)

Figure 7. Voltage and current waveform for Conventional DSTATCOM

(a)Without DSTATCOM (b) With DSTATCOM

In case of Without DSTATCOM, there is no compensation i.e. compensation current is zero. The load current and source current waveform is exactly same and is non-sinusoidal in nature due to non-linear load at the PCC. The waveform of terminal voltage is sinusoidal. A low value of DC link voltage (2V) appears across DC capacitor. But when the DSTATCOM is put in operation with the distribution system, Compensation occurs i.e. compensation current is non-zero value. Load current is unbalanced and non-linear but source current is pure sinusoidal and in phase with terminal voltage which is also sinusoidal nature. Hence power factor will be improved to unity when DSTATCOM is connected to the distribution system. DC link voltage across DC capacitor is $70 \mathrm{~V}$ approximately which is large from previous case. Figure 8 indicates THD spectrum of source current for conventional DSTATCOM under Indirect PI control by considering without and with DSTATCOM. Without DSTATCOM source current THD is $11.13 \%$ but when the DSTATCOM is switched on, the THD is reduced to $2.72 \%$. 

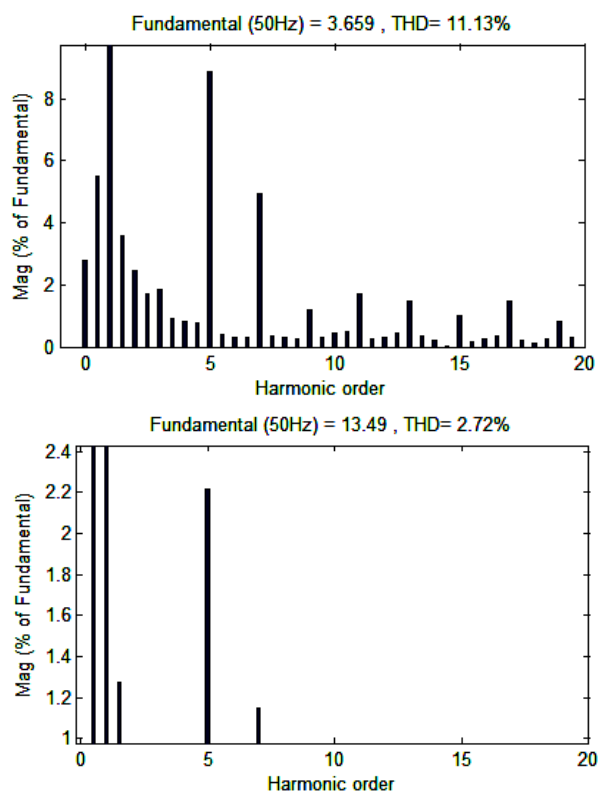

(a)

(b)

Figure 8. THD spectrum of source current for conventional DSTATCOM (a)Without DSTATCOM (b) With DSTATCOM
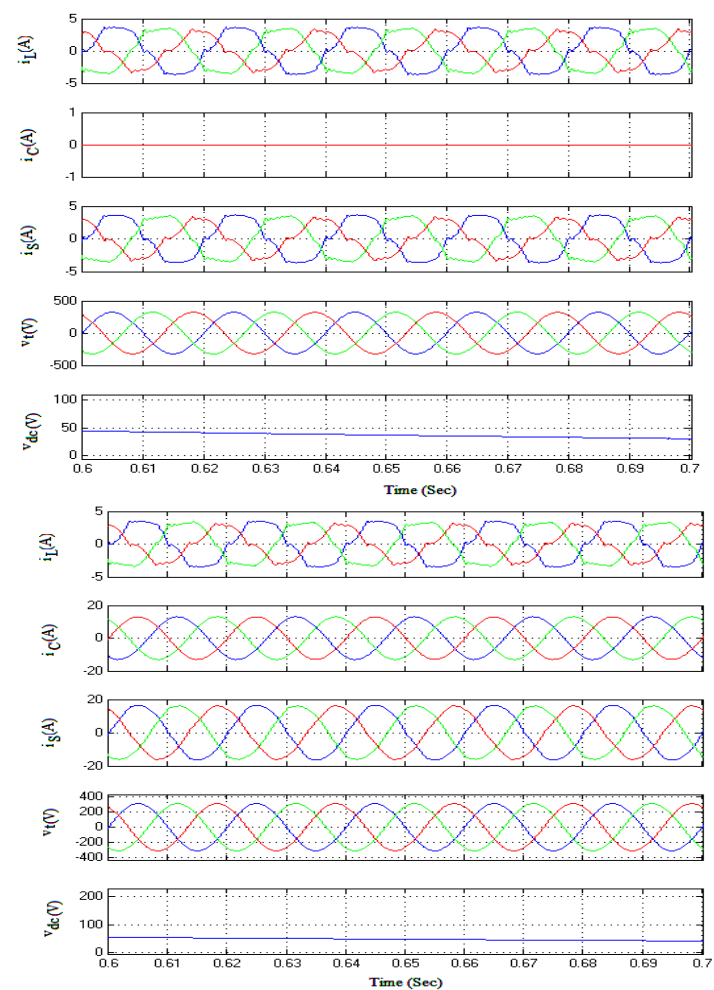

(a)

Figure 9. Voltage and current waveform for Modified DSTATCOM (a)Without DSTATCOM (b) With DSTATCOM 
Now the performance characteristic of the Modified DSTATCOM system is tested under Indirect PI control technique. Figure 9 indicates various voltage and current waveform for Modified DSTATCOM in without and with DSTATCOM condition.

In this topology before compensation, compensation current is zero. Both source current and load current are unbalanced and non-linear. Terminal voltage is sinusoidal with a magnitude of $300 \mathrm{~V}$. DC link voltage is varying from $40 \mathrm{~V}$ to $30 \mathrm{~V}$. But after compensation, compensation current occurs and its value is 13A. Load current remains unbalanced and nonsinusoidal. However source current and terminal voltages have different magnitude but both are in phase which depicts power factor improvement on supply side. A small variation of DC link voltage occurs from $50 \mathrm{~V}$ to $40 \mathrm{~V}$. Figure 10 represents THD spectrum of source current for Modified DSTATCOM topology under Indirect PI control. THD of source current is reduced from $11.13 \%$ without DSTATCOM to $2.36 \%$ with DSTATCOM.
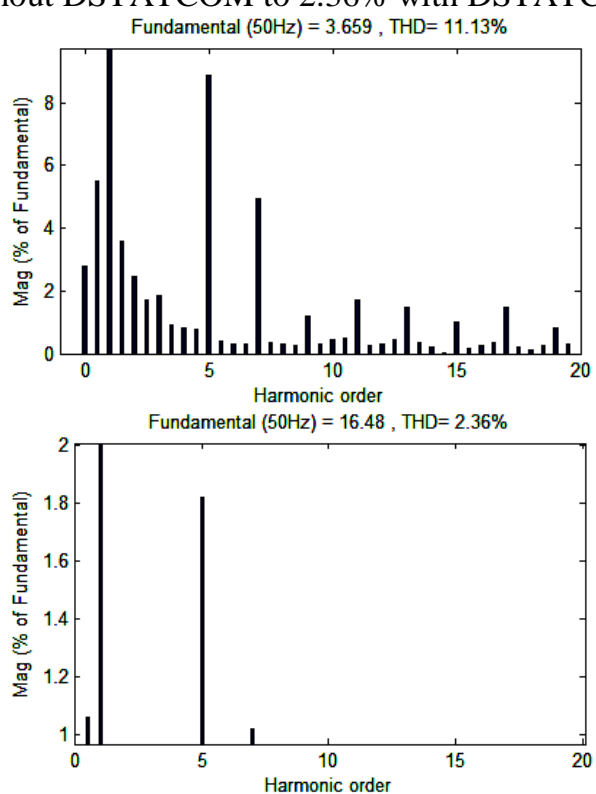

(a)

(b)

Figure 10. THD spectrum of source current for Modified DSTATCOM (a)Without DSTATCOM (b) With DSTATCOM

B. Source current harmonic reduction and power factor Improvement under synchronous reference frame control

Synchronous reference frame control technique is adopted for conventional and modified DSTATCOM systems in order to test source current harmonic compensation and power factor improvement on supply side. Initially, performance of conventional DSTATCOM topology will be discussed. Figure 11 indicates various current and voltage waveform for the conventional DSTATCOM topology under synchronous reference frame control. 


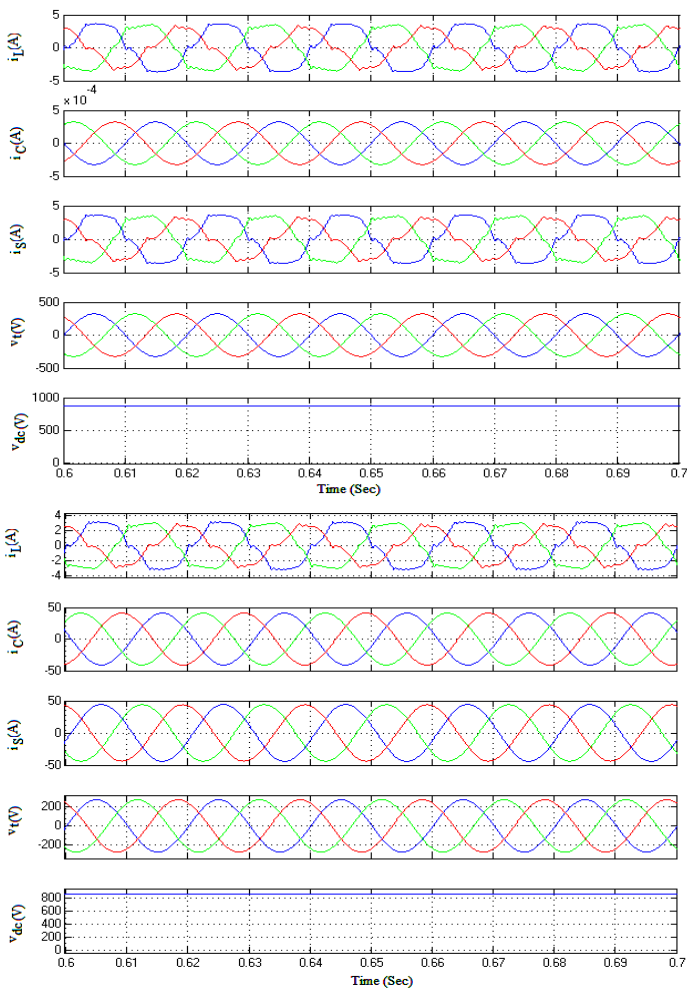

(a)

(b)

Figure 11. Voltage and current waveform for conventional DSTATCOM (a)Without DSTATCOM (b) With DSTATCOM
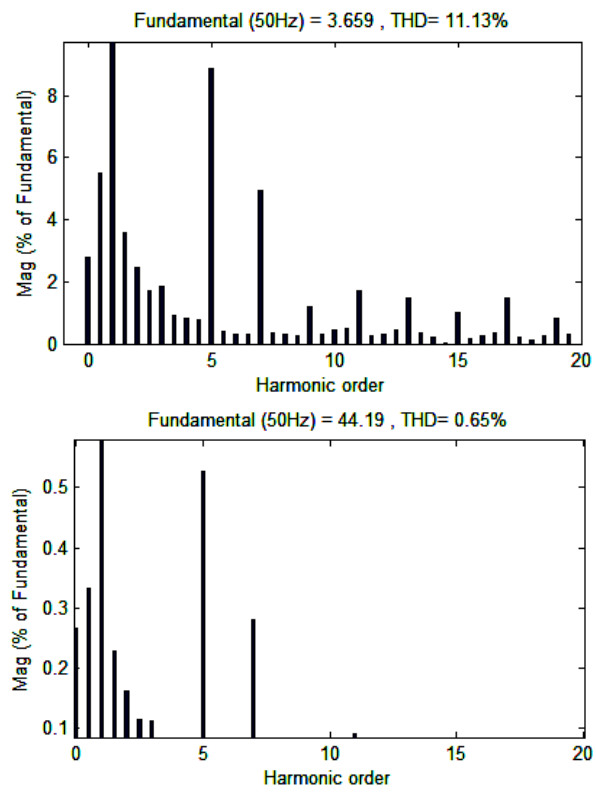

(a)

(b)

Figure 12. THD spectrum of source current for conventional DSTATCOM

(a)Without DSTATCOM (b) With DSTATCOM 
Before switching of the DSTATCOM with the distribution system, the compensation current is approximately zero. Unbalanced and non-linear load create load current and source current waveform equal but non-sinusoidal with a magnitude of $4 \mathrm{~A}$. The terminal voltage at PCC is sinusoidal with a magnitude of $320 \mathrm{~V}$. The DC link voltage has a constant value of $870 \mathrm{~V}$. After switching of the DSTATCOM with the distribution system, compensation occurs with a compensation current of 40A. Load current remains unbalanced and non-sinusoidal. Source current and terminal voltage waveform are balanced and sinusoidal with a negligible phase difference between them and hence power factor improvement is achieved. The DC link voltage remains unaltered with a magnitude of $870 \mathrm{~V}$ which is exactly same as in the previous DC link value. Figure 12 represents THD spectrum of source current for conventional DSTATCOM topology under Synchronous reference frame control. THD of source current is reduced from $11.13 \%$ without DSTATCOM to $0.65 \%$ with DSTATCOM.

Now modified DSTATCOM topology has been tested for power quality improvement in terms of harmonic compensation and power factor improvement. Figure 13 indicates its various current and voltage waveform for the modified DSTATCOM topology under synchronous reference frame control.
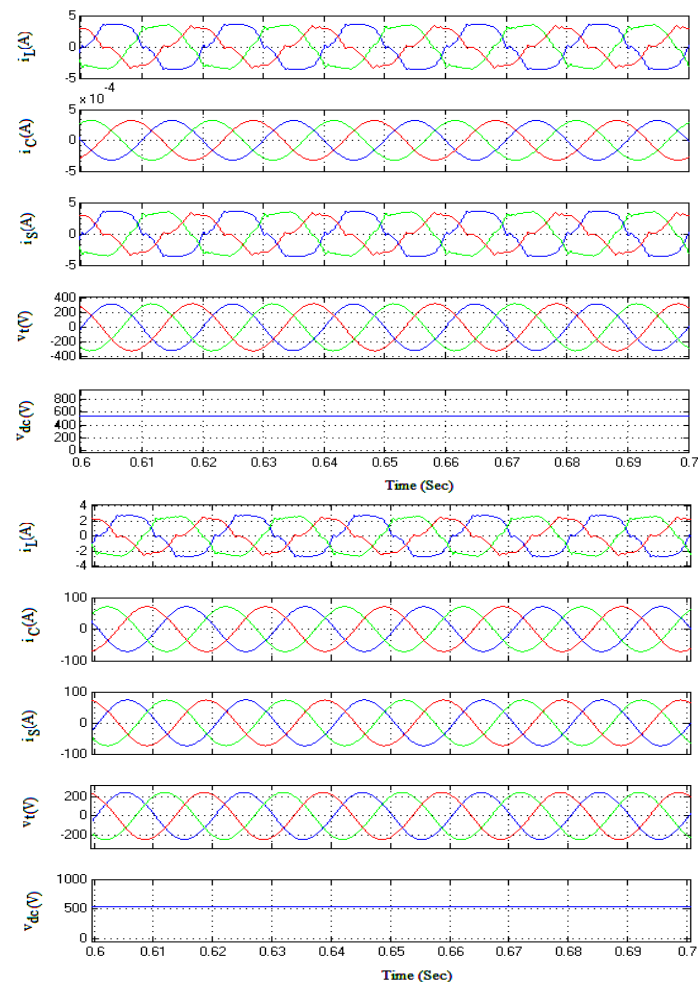

(a)

(b)

Figure 13. Voltage and current waveform for modified DSTATCOM

(a)Without DSTATCOM (b) With DSTATCOM

Before compensation, the compensation current is approximately zero. The wave shape of load current and source current are similar and non-sinusoidal due to unbalanced and nonlinear load. The terminal voltage waveform is sinusoidal with a magnitude of $320 \mathrm{~V}$. The voltage across DC capacitor is DC link voltage and has a constant value of $540 \mathrm{~V}$. After compensation, compensating current is injecting at PCC which is sinusoidal with a value of 70 A. As always source current and terminal voltage are in phase having different magnitudes after compensation which depicts power factor improvement on source side. DC link voltage 
remains unaltered i.e. 540V. Figure 14 shows current THD spectrum of the source for modified DSTATCOM topology under synchronous reference frame control in before and after compensation mode. The THD of source current is reduced from $11.13 \%$ before compensation to $0.31 \%$ after compensation.
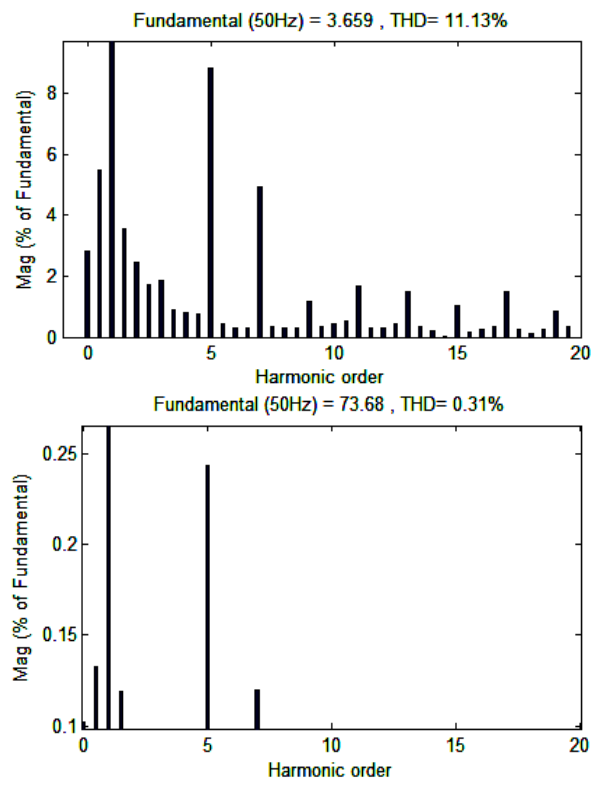

(a)

(b)

Figure 14. THD spectrum of source current for modified DSTATCOM (a)Without DSTATCOM (b) With DSTATCOM

Table 2 represents final performance evaluation of percentage THD of source current for conventional as well as modified DSTATCOM Topology under synchronous reference frame and indirect PI control. Figure 15 represents chartable view of source current THD of DSTATCOM Topologies in synchronous reference frame and indirect PI control.

Table.2 THD of Source Current for DSTATCOM Topology

\begin{tabular}{l|c|c|c|c}
\hline \multirow{2}{*}{$\begin{array}{l}\text { DSTATCOM } \\
\text { Topology }\end{array}$} & \multicolumn{2}{|c|}{$\begin{array}{c}\text { Synchronous Reference Frame } \\
\text { Control }\end{array}$} & \multicolumn{2}{c}{ Indirect PI Control } \\
\cline { 2 - 5 } & $\begin{array}{c}\text { Without } \\
\text { DSTATCOM(\%) }\end{array}$ & $\begin{array}{c}\text { With } \\
\text { DSTATCOM }(\%)\end{array}$ & $\begin{array}{c}\text { Without } \\
\text { DSTATCOM }(\%)\end{array}$ & $\begin{array}{c}\text { With } \\
\text { DSTATCOM(\%) }\end{array}$ \\
\hline $\begin{array}{l}\text { Conventional } \\
\text { DSTATCOM }\end{array}$ & 11.13 & 0.65 & 11.13 & 2.72 \\
\hline $\begin{array}{l}\text { Modified } \\
\text { DSTATCOM }\end{array}$ & 11.13 & 0.31 & 11.13 & 2.36 \\
\hline
\end{tabular}




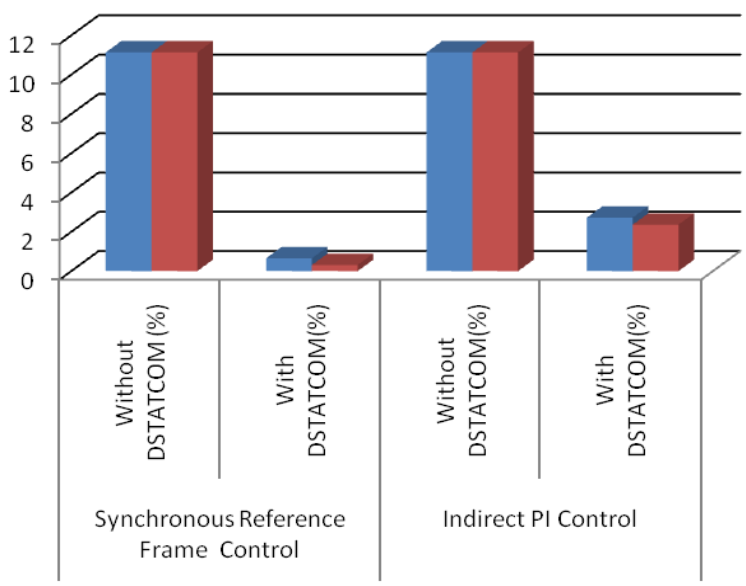

n Conventional DSTATCOM

- Modified DSTATCOM

Figure 15. Chartable form of Source Current THD of DSTATCOM topologies

\section{Conclusions}

The analysis, simulation, and implementation of conventional and modified DSTATCOM topology consisting of a VSI with a two-winding transformer have been carried out, and their performances have been tested for current harmonic elimination and power factor improvement on the source side. It has been found that synchronous reference frame control technique gives better dc bus voltage regulation for the DSTATCOM as compared to Indirect PI technique. The source current harmonic elimination in synchronous reference frame control is also better than Indirect PI technique. The percentage harmonic reduction in both control strategies successfully fulfills the criteria of IEEE-519 standard. Moreover it has been observed that in the modified DSTATCOM topology, the THD value of source current is lower than conventional DSTATCOM topology and hence modified DSTATCOM topology is a good choice for more power quality improvement.

\section{Acknowledgements}

This work has been financially supported by the NIT Sikkim, MHRD, Govt. of India, New Delhi.

\section{References}

[1]. T. J. E. Miller, Reactive Power Control in Electric Systems, USA: Wiley,1982.

[2]. G. T. Heydt, Electric Power Quality, 2nd ed. USA: Stars in a Circle, 1994.

[3]. J. Arrilaga, N. R. Wattson, S. Chen, Power System Quality Assessment, USA: Wiley, 2000.

[4]. Sankaran, Power Quality, USA: CRC Press, 2001.

[5]. A. Ghosh, G. Ledwich, Power quality enhancement using custom power devices, London: Kluwer Academic Publishers, 2002.

[6]. R. C. Dugan, M. F. McGranaghan, H. W. Beaty, Electric Power Systems Quality, 2nd ed. USA: McGraw Hill, 2006.

[7]. Moreno-Munoz, Power Quality: Mitigation Technologies in a Distributed Environment, Germany: Springer-Verlag, 2007.

[8]. K. R. Padiyar, FACTS Controllers in Transmission and Distribution. New Delhi, India: New Age International, 2007.

[9]. H. Akagi, E.H. Watanabe, M. Aredes, Instantaneous Power Theory and Applications to Power Conditioning. Hoboken, NJ: Wiley, 2007.

[10]. H.-L. Jou, K.-D. Wu, J.-C. Wu, W.-J. Chiang, “A three-phase four wire power filter comprising a three-phase three-wire active filter and a zig-zag transformer", IEEE Trans. Power Electron., vol. 23, no. 1, pp. 252-259,2008. 
[11]. S.N. Sivanandam, S.N. Deepa, Principle of Soft Computing, New Delhi: Wiley India Ltd, 2010.

[12]. Rogor Jang Jyh Shing, Tsai Sun Chuen, Eiji Mizutani, A Computational Approach to Learning and Machine Intelligence, Delhi: Person Education Asia,2008.

[13]. Parmod Kumar, Alka Mahajan, "Soft computing techniques for the control of an active power filter", IEEE Transactions on Power Delivery, vol. 24, no. 1, pp.452-461, 2009.

[14]. Avik Bhattacharya, Chandan Chakraborty, "A shunt active power filter with enhanced performance using ANN-based predictive and adaptive controllers", IEEE Transactions on Industrial Electronics, vol. 58, no. 2, pp. 421-428, 2011.

[15]. Mahesh K. Mishra, K. Karthikeyan, "Design and analysis of voltage source inverter for active compensators to compensate unbalanced and non-linear loads", in 8th International Power Engineering Conference, pp. 649-654, 2007.

[16]. N. Singh, P. Rastgoufard, B. Singh, A. Chandra, K. Al-Haddad, "Design, simulation and implementation of three-pole/four-pole topologies for active filters", IEE Proceedings Electric Power Applications, Vol. 151, no. 4, pp. 467 - 476, 2004.

[17]. Nagesh Geddada, Srinivas Bhaskar Karanki, Mahesh K. Mishra, B. Kalyan Kumar, "Modified Four Leg DSTATCOM Topology for Compensation of Unbalanced and Nonlinear Loads in Three Phase Four wire System", Proceedings of the 2011-14 European Conference on Power Electronics and Applications (EPE 2011), 1 - 10, 2011.

[18]. S V Ravi Kumar, S Siva Nagaraju, "Simulation of D-STATCOM and DVR in power systems", ARPN Journal of Engineering and Applied Sciences, 2(3), pp7-13, 2007.

[19]. Pradeep Kumar, Niranjan Kumar, A K Akella, "A Simulation Based Case Study for Control of DSTATCOM", ISA Transactions, 53,767-775, 2014.

[20]. K Duffey Christopher, P Stratford Ray, "Update of harmonic standard IEEE-519: IEEE recommended practices and requirements for harmonic control in electric power systems", IEEETrans Ind Appl, 25(6),1025-34,1989.

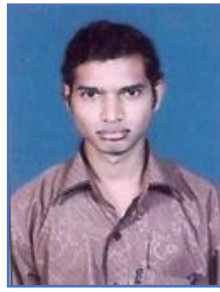

Pradeep Kumar born in India in 1985. He received the B.E.(Electrical Engg) from GEC Bilaspur, India and M.Tech. (Electrical Engg) with specialization of Control System from COEP, Pune, India in 2008 and 2010 respectively. His Ph.D. Degree is in Electrical Engg. Department, NIT Jamshedpur ,India in 2017. He joined NIT Sikkim as an assistant professor. His main research interests are control system, renewable energy system and power quality. 